\title{
Modification of Starches with Different Amylose/ Amylopectin Ratios Using the Dual Approach with Hydroxypropylation and Subsequent Acid Thinning-III: Impacts on Gel Characteristics
}

\author{
Marco Ulbrich* and Eckhard Flöter
}

\begin{abstract}
Starches with different amylose (AM)/amylopectin (AP) ratios (waxy potato: WxPS, regular potato: PS, high AM corn: HACS) are subjected to hydroxypropylation (HP, two levels) and subsequent acid-thinning (AT) to produce dual modified samples. Pastes of the starch samples (native; single modification: HP and AT, respectively; dual modification) are prepared by pressure cooking to two different starch concentrations (C) $(6 \%$ and $9 \% \mathrm{w} / \mathrm{w})$ and systematically investigated especially in terms of light transmittance $(T)$ and specific gel characteristics after long-term cold storage ( $168 \mathrm{~h}$ at $5.5 \pm$ $1.5^{\circ} \mathrm{C}$ ). The data are evaluated statistically (i.a. analysis of variance, ANOVA) and significant effects are identified. Indeed, the gel strength correlates positively with the AM content of the starch and C, but the HP eliminates the ability of the starch to gel in most cases. The improved $T_{\text {gel }}$ due to HP is accompanied by extensive loss of mechanical strength in most cases, which is not compensated by the partial molecular degradation via AT. Hence, a synergistic effect of both modifications is not revealed. The synergistic implementation of a starch with the desired properties by preparing mixtures is not revealed during the present examinations.
\end{abstract}

\section{Introduction}

The polysaccharide starch is used for many applications in industrial food production, in particular for texturing purposes. Besides rheological properties like special flow characteristics of the starch pastes, which can control the processability, the gel formation in particular is one of the main attributes. High mechanical strength of the gel as well as high (T) or the clarity of the system, respectively, are important intentional functional features in this context. ${ }^{[1]}$

Dr. M. Ulbrich, Prof. E. Flöter

Chair of Food Process Engineering

Department of Food Technology and Food Chemistry, Technische

Universität Berlin

Office GC2, Seestraße 13, Berlin D-13353, Germany

E-mail:marco.ulbrich@tu-berlin.de

The ORCID identification number(s) for the author(s) of this article can be found under https://doi.org/10.1002/star.202000146

(C) 2020 The Authors. Starch - Stärke published by Wiley-VCH GmbH. This is an open access article under the terms of the Creative Commons Attribution License, which permits use, distribution and reproduction in any medium, provided the original work is properly cited.

DOI: 10.1002/star.202000146
The AM/AP ratio and specific chemical properties, which are inherent from the botanical source of the starch, determine the gelation behavior and corresponding gel characteristics of systems based on a native starch (no modification). Since the gelation depends mostly on the successive partial retrogradation of the AM fraction including its development of double helical segments and subsequent crystallization, particularly high AM content starches display rapid thickening and the formation of mechanically strong gels. ${ }^{[2,3]}$ The AP fraction is presumably embedded within the 3D AM network. ${ }^{[4-7]}$ In contrast, most regular starches form weak gels or require long-term storage for certain reinforcement of the structure, ${ }^{[2]}$ and the waxy starches are usually unable to gel due to absence of $\mathrm{AM}^{[3]}$ Very probably due to steric hindrance, the highly branched structure of the AP inhibits appreciable intermolecular interactions with corresponding retrogradation and the development of a macroscopic network structure and solidification. However, the development of microstructures of waxy starches to a certain extent based on partial retrogradation was impressively revealed recently. ${ }^{[8]} \mathrm{Nev}-$ ertheless, widely failing re-crystallization in the starch solution prevents the system to turn turbid concurrently. ${ }^{[9]}$

The partial molecular degradation of starch in the granular state by means of AT using mineral acids is an established method reducing the hot paste viscosity of the starch product. Particularly the molecular size reduction of the AP and accompanied generation of branched dextrins facilitates the comprehensive formation of an AM network by diminution of the interference effect of the AP. Increased ability to form stable gels due to AT modification primarily applies to regular or common starches, respectively, having an AM/AP ratio of about 25/75. ${ }^{[10]}$ A corresponding partial molecular cleavage of starch genotypes with strongly different AM/AP ratio, that is, waxy starches (all-AP starch) or high AM varieties (e.g., about 50\% $\mathrm{w} / \mathrm{w}$ or more AM), however, implicates no improvement of the gelling characteristics compared to the initial starch material. ${ }^{[3]}$ HP of starch lowers the possibility of polymer-polymer interaction by introducing the HP-groups which act as spacers. ${ }^{[1]}$ Compared to the corresponding non-substituted (native) starch, 
the reduced tendency to retrogradation potentially decreases the ability to form a gel network. However, lowered intensity of inter-molecular associations is accompanied by a lower level of crystallization. Hence, a supposed lower number of scattering points and potentially shorter retrogradation zones presumably increase(s) the $T$ even after long-term cold storage of the aqueous starch system $\left(T_{\text {gel }}\right)$. The modification of the starch by HP advancing the gel clarity is assumed to be counter to gelation and development of high mechanical gel strength or reduces the specificity of the characteristic, respectively. Based on that, the dual modification of starch using HP and subsequent AT was hypothesized to be a compromise between the desired reduction of retrogradation on the one hand $(\mathrm{T})$ and necessary retrogradation to a certain extent on the other hand (AM-network).

The present study is the third part of a series which is mainly focused on the functional properties clarity and gel strength of previously prepared starch products..$^{[1]}$ Starches with markedly differing AM/AP ratios (WxPS, PS, and HACS) underwent a systematical chemical modification using HP first (two levels: HP-1 and HP-2), followed by an AT. All various parameters control the molecular properties comprehensively, which on their part impact several (techno-) functional properties of the single- and dual-modified starch samples.

\section{Experimental Section}

\subsection{Starch and Modified Starch Samples}

Commercial native starches (WxPS [Empure AKS 100] and PS [Superior], Emsland-Stärke GmbH, Emlichheim, Germany; HACS [Hylon VII], Ingredion Germany GmbH, Hamburg, Germany) with different AM contents were used. The detailed description of the modification is provided in a previous study. ${ }^{[1]}$ To prepare the dual-modified starch products, the starches first underwent a HP (two different levels of MS; HP-1 and HP-2 referring to low and high MS, respectively), and were subsequently AT. Corresponding single-modified samples (HP and AT) were also produced, and are part of the examination. The denotations and selected molecular data of the starch samples are provided elsewhere, ${ }^{[1,12]}$ including, among others, MS, $M_{\mathrm{w}}$ starch total and $M_{\mathrm{w}}$ AM fraction. ${ }^{[13,14]}$ Deionized water was used for all experiments.

\subsection{Paste Preparation}

The preparation of starch solutions was made according to Ulbrich and Flöter. ${ }^{[15]}$ Freshly prepared pastes of different C $(6 \%$ and $9 \% \mathrm{w} / \mathrm{w}$, respectively) were used for the experiments.

\subsection{Light Transmittance of the Solutions and the Gels}

Clarity or $T$, respectively, of the freshly prepared starch solutions $\left(T_{\text {sol }}\right)$ as well as the stored systems $\left(T_{\text {gel }}\right)$ was determined as described elsewhere ${ }^{[10]}$ with modifications. The starch solution (6\% and $9 \% \mathrm{w} / \mathrm{w}$, respectively) was filled in cuvettes (poly(methyl methacrylate); PMMA, $4 \mathrm{~mL}$, Rotilabo, Carl Roth GmbH \& Co. KG, Karlsruhe, Germany) before measurement of $T_{\mathrm{sol}}$. To determine the $T_{\mathrm{gel}}$, the respective freshly prepared solution was filled into the cuvettes, capped to prevent drying-out as well as shrinking, and stored for $168 \mathrm{~h}$ at $5.5 \pm 1.5^{\circ} \mathrm{C}$ before being analyzed. $T$ was determined at $\lambda=650 \mathrm{~nm}$ using a spectrophotometer (Jenway 6505 UV/Visible, Stone Staffordshire, UK) and deionized water as the reference.

\subsection{Gel Preparation and Gel Strength}

Gels were prepared on the basis of freshly disintegrated starches (6\% and $9 \% \mathrm{w} / \mathrm{w}$, respectively, see Section 2.2 ) and characterized according to the description elsewhere ${ }^{[10]}$ with modifications. After casting (diameter $30.0 \mathrm{~mm}$, height $20.0 \mathrm{~mm}$ ) and storage for $168 \mathrm{~h}$ at $5.5 \pm 1.5^{\circ} \mathrm{C}$, a fresh and planar surface was realized by cutting the gels. The mechanical strength was determined by compression using a texture analyzer (Test Control II, Z1.0, $1 \mathrm{kN}$, Zwick/Roell, Ulm, Germany) equipped with a cylindrical penetration probe (diameter $25.4 \mathrm{~mm}$ ). The peak force $(\mathrm{N})$ of the first penetration was taken as gel strength. Gel preparation and measuring its hardness were carried out in triple determination. The arithmetic average and the corresponding standard deviation were calculated.

\subsection{Non-Freezable Bound Water in Stored Starch Systems (Gels)}

The water binding of the stored starch systems (gels; $6 \%$ and $9 \%$ $\mathrm{w} / \mathrm{w}$; storage for $168 \mathrm{~h}$ at $5.5 \pm 1.5^{\circ} \mathrm{C}$ ) was determined based on differential scanning calorimetry (DSC) freezing experiments according to the description elsewhere ${ }^{[10]}$ with modifications. Within the present study, the water binding capacity $\left(\mathrm{WBC}_{\text {gel }}\right.$ ) was defined as the specific non-freezable fraction $\left(w_{n f}\right)$ of the water bound to the starch polysaccharides and expressed in $g$ nonfreezable bound water per $g$ dry starch. The $w_{\text {nf }}$ was calculated according to $w_{c}\left(\Delta H_{\text {sample }} / \Delta H_{\text {bulk water }} \cdot w_{c}\right)$, where $w_{c}$ is the total water content related to the starch ( $6 \% \mathrm{w} / \mathrm{w}: w_{\mathrm{c}}=15.67 \mathrm{~g} \mathrm{~g}^{-1}, 9 \%$ $\left.\mathrm{w} / \mathrm{w}: w_{\mathrm{c}}=10.11 \mathrm{~g} \mathrm{~g}^{-1}\right), \Delta H_{\text {sample }}$ the transition enthalpy of the water in the gel (cooling run; liquid $\rightarrow$ solid), and $\Delta H_{\text {bulk water }}$ the transition enthalpy of bulk water (cooling run; liquid $\rightarrow$ solid).

The DSC experiments were performed using a DSC 204 F1 Phoenix fitted with an intracooler (Netzsch, Selb, Germany) in duplicate with a scanning rate of $10 \mathrm{~K} \mathrm{~min}^{-1}$ and air as the reference. Conditions were: start at ambient temperature $\left(20 \pm 2{ }^{\circ} \mathrm{C}\right)$ and equilibrium to $20^{\circ} \mathrm{C}$ with isotherm for $2 \mathrm{~min}$, cooling to $-50^{\circ} \mathrm{C}$ with isotherm for $2 \mathrm{~min}$ and subsequent heating to $50^{\circ} \mathrm{C}$ with isotherm for $2 \mathrm{~min}$, followed by cooling to $20^{\circ} \mathrm{C}$. The thermograms were evaluated by means of Netzsch Proteus thermal analysis Version 4.8.0 software.

\subsection{Data Evaluation}

The impact of the different parameters (AM [starch type], HP, $\mathrm{AT}$, and C) on the functional properties was investigated based on an experimental design $(n=36)$ using Statgraphics Plus 5.0 software. The analysis distinguished between $T$ of the aqueous starch 
Table 1. ANOVA for the impacts AM (starch type), HP, AT, and C on the transmittance of the aqueous system $\left(T_{\text {sol }}\right.$ and $\left.T_{\text {gel }}\right)$, the gel strength, and the $W_{B C} C_{\text {gel }}\left(w_{n f}\right)$. Boldface type: statistically significant effect with a $95.0 \%$ level of significance.

\begin{tabular}{|c|c|c|c|c|c|}
\hline \multirow{3}{*}{ Impact } & & \multicolumn{4}{|c|}{$p$-Value } \\
\hline & & \multicolumn{2}{|c|}{ Transmittance ${ }^{a}$ ) } & \multirow[t]{2}{*}{ Gel strength } & \multirow{2}{*}{$\frac{W B C}{\left.w_{n f}^{b}\right)}$} \\
\hline & & $T_{\text {sol }}$ & $T_{\text {gel }}$ & & \\
\hline \multirow[t]{4}{*}{ Single } & $\left.A M^{c}\right)$ & 0.0000 & 0.0000 & 0.0005 & 0.1570 \\
\hline & $\left.H P^{d}\right)$ & 0.0028 & 0.0000 & 0.0001 & 0.4870 \\
\hline & $\left.A T^{e}\right)$ & 0.8203 & 0.5903 & 0.9922 & 0.5425 \\
\hline & $c^{f_{1}}$ & 0.0222 & 0.0008 & 0.0289 & 0.0001 \\
\hline \multirow[t]{6}{*}{ Interaction } & AM-HP & 0.4518 & 0.0000 & 0.0001 & 0.8477 \\
\hline & AM-AT & 0.2663 & 0.8313 & 0.5912 & 0.4773 \\
\hline & $A M-C$ & 0.8190 & 0.0171 & 0.0464 & 0.6102 \\
\hline & HP-AT & 0.4723 & 0.0264 & 0.9967 & 0.1955 \\
\hline & $\mathrm{HP}-\mathrm{C}$ & 0.6509 & 0.1620 & 0.0212 & 0.2625 \\
\hline & AT-C & 0.6034 & 1.0000 & 0.7535 & 0.0993 \\
\hline
\end{tabular}

a) Determination on the basis of the freshly prepared solution $\left(T_{\text {sol }}\right)$ and after storage $\left(T_{\text {gel }}\right)$; ${ }^{\text {b) }}$ Non-freezable water fraction; calculation based on DSC experiments; freezing: cooling mode; ${ }^{c)}$ Starch types with different AM contents (WxPS, PS, and

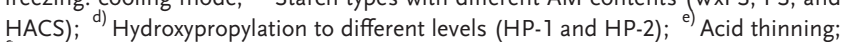
f) Starch concentration ( $6 \%$ and $9 \% \mathrm{w} / \mathrm{w}$ ) of pastes and gels, respectively.

system $\left(T_{\text {sol }}\right.$ and $\left.T_{\text {gel }}\right)$, gel strength, and $\mathrm{WBC}_{\text {gel }}\left(w_{\text {nf }}\right)$. The values for the probability of error ( $p$-value) are listed in Table 1 . With a $p$-value less than 0.05 , the factor investigated had a statistically significant effect with a $95.0 \%$ level of significance (boldface type in Table 1). Additionally, selected results from the statistical evaluation were summarized in mean and interaction diagrams $\left(T_{\text {sol }}\right.$ and $T_{\text {gel }}$, respectively, gel strength and $w_{\text {nf }}$ ) showing the calculated means of each category (AM [starch type]: WxPS, PS, and HACS; HP: without HP-1 and HP-2; AT: without and AT; C: $6 \%$ and $9 \%)$ and the confidence interval with a $95.0 \%$ confidence level. The absence of overlapping in the confidence intervals in the mean diagrams indicates a statistically significant difference in the observed categories with a $95.0 \%$ level of confidence.

\section{Results and Discussion}

\subsection{Statistical Analysis}

The results from the statistical analysis of the data ( $p$-values) are listed in Table 1 . In contrast to AT, the starch type (AM), HP as well as C were statistically significant impacts on both $T_{\text {sol }}$ and $T_{\text {gel }}$, and the mechanical strength. Moreover, some combinations of the impacts were found to be statistically significant (Table 1, impact: interaction). In terms of $\mathrm{WBC}_{\text {gel }}$, the $w_{\mathrm{nf}}$ was impacted very significantly by $C$ (Table 1 ). The special influence on the specificity of each variable ( $T$, gel strength, and $w_{\text {nf }}$ ) is displayed and discussed in detail in the respective sections below.

\subsection{Clarity of the Aqueous Starch Systems}

The clarity of the concentrated aqueous starch systems $(6 \%$ and $9 \% \mathrm{w} / \mathrm{w}$, respectively) was determined on the basis of the $T$, differentiated to the freshly prepared paste $\left(T_{\mathrm{sol}}\right)$ and the stored system, which was gelled in some cases $\left(T_{\text {gel }}\right)$. Figure 1 shows the mean $(\mathrm{A}-\mathrm{D})$ and selected interaction diagrams $(\mathrm{E}-\mathrm{H})$ from the statistical evaluation of the data. Since $T_{\text {gel }}$ was found to be usually lower than $T_{\text {sol }}$, the reduction of $T$ as a result of the storage is clearly obvious from the diagrams. Reasons for this were presumably retrogradation effects, triggered and amplified by both the reduced temperature $\left(5.5 \pm 1.5^{\circ} \mathrm{C}\right)$ and extended storage duration $(168 \mathrm{~h})$. A detailed analysis of the $T$ and the specific change of it due to storage $(\Delta T)$ and accompanied sol-gel transition in some cases is provided below (Figure 2). The starch type was found to have a statistically significant impact on the $T(p<0.05$, Table 1). The $T$ of the potato-based starches was higher compared to the HACS samples (Figure 1A). Reasons were probably the comparatively high AP content of WxPS and PS as well as the phosphate groups incorporated into the AP structure on the one hand (WxPS: $0.066 \%$ P; ${ }^{[16]}$ PS: $0.052 \%$ P, ${ }^{[9]} 0.075 \%$ P, ${ }^{[16]} 0.089 \%$ P; ${ }^{[17]}$ HACS: $\left.0.020 \% \mathrm{P}^{[17]}\right) \cdot{ }^{[18]}$ The latter suppresses, at least partially in certain conditions, strong inter-molecular interactions due to electrostatic repulsion. ${ }^{[19,20]}$ On the other hand, the high AM content of the HACS, which is moreover positively correlated to the lipid content of the cereal starch, ${ }^{[21-25]}$ leads to rapid inter-chain interaction, particularly of the AM (retrogradation and crystallization), and the formation of AM-lipid complexes. ${ }^{[26-28]}$ Both factors increase the light scattering and turbidity of the system, consequently reducing $T .{ }^{[29]}$

The effect of the HP was statistically significant (95\% level of significance) on the $T$, since the $p$-values (ANOVA, Table 1) were below 0.05 . The respective mean diagram (Figure 1B) shows $T$ increasing with an increasing level of HP. The main reason is suggested to be the introduction of the HP-groups in the molecule structure acting as a spacer, hence reducing the ability of the polymers to retrograde. Since the increase of MS from grade 1 (HP-1) to grade 2 (HP-2) did not lead to further remarkable enhancement of $T$, the HP aiming at an MS of about 0.10 maximally (HP-1 ${ }^{[1]}$ ) seems to be optimal. A significantly higher specific amount of HP-groups does not impact the clarity appropriately. The interaction plot in Figure $1 \mathrm{E}$ shows that the reduction of the $T$ is remarkable, particularly for the potato starch-based samples without HP. Especially the drastic reduction of $T$ due to storage of the WxPS was not initially expected. However, probably the comparatively long AP branch chains ${ }^{[1]}$ with an average degree of polymerization $\left(\mathrm{DP}_{\mathrm{w}}\right)$ of about 29 undergo a certain interaction related to double-helix formation ${ }^{[8]}$ and subsequent partial crystallization, despite the high degree of polymer branching. The AT had no effect on the $T$ (Table 1 ), which is additionally confirmed by Figure 1C,F,H. However, the enhancement of C from $6 \%$ to $9 \% \mathrm{w} / \mathrm{w}$ resulted in a significant decrease of both $T_{\text {sol }}$ and $T_{\text {gel }}$ (Figure 1D). Based on that, the dry matter content is necessarily correlated to the turbidity of the system. This was distinctive for the freshly prepared solution $\left(T_{\text {sol }}\right)$ as well as the potato-based stored systems $\left(T_{\text {gel }}\right)$ as shown in Figure $1 \mathrm{G}$. In contrast, the variation of $\mathrm{C}$ did not impact $T_{\text {gel }}$ of the HACS samples, independent of the type (no, HP, AT and HP-AT) and degree of modification (HP-1 and HP-2), since all stored systems were opaque having a $T$ of about $0 \%$ (Figure 2). Increasing starch paste clarity as a result of HP was reported for different starches and degrees of modification earlier, for example, by Pal et al. ${ }^{[30]}$ (corn 

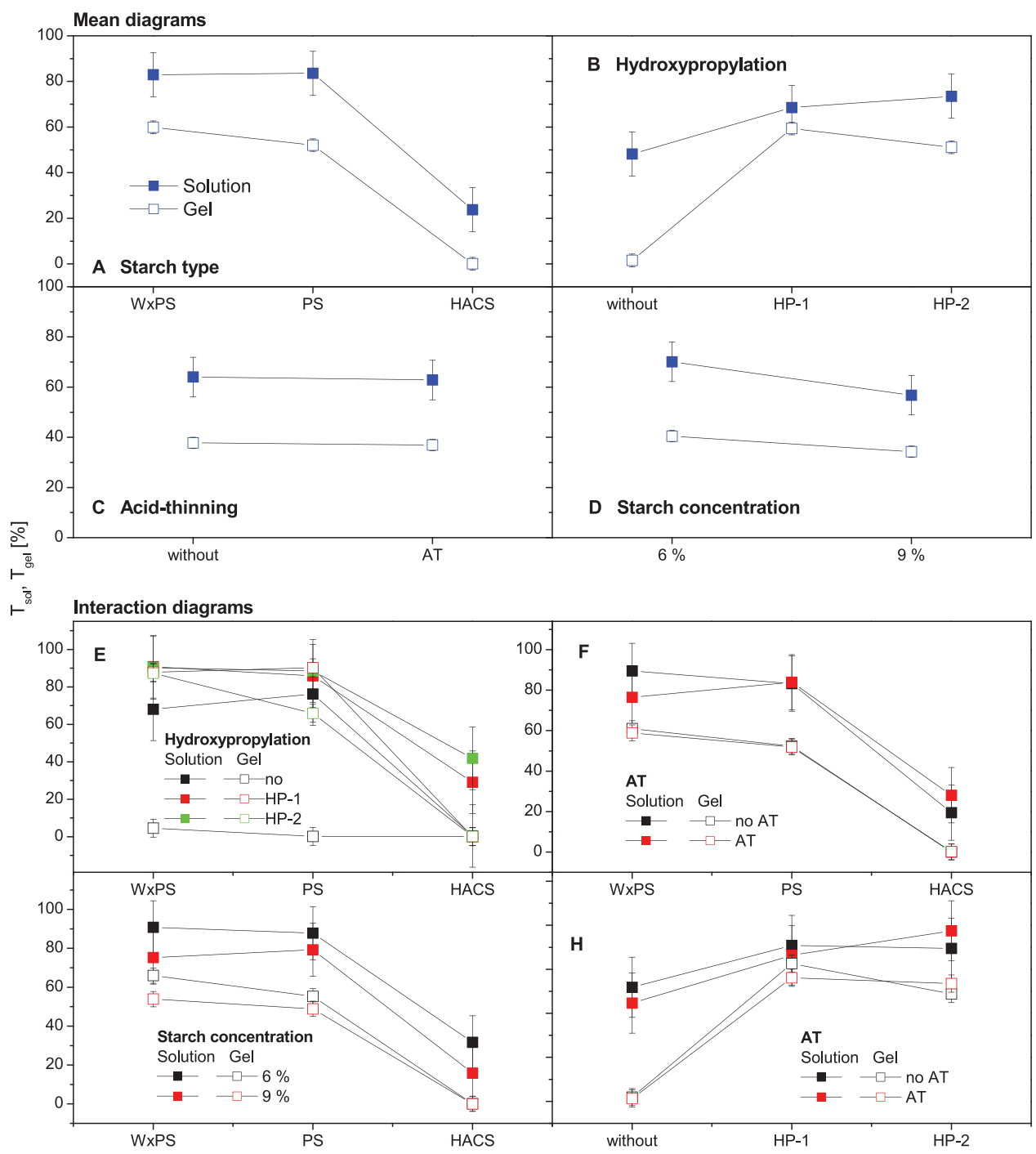

Figure 1. Mean (A-D) and selected interaction diagrams (E-H) with a $95 \%$ confidence interval of the impacts of starch type (WxPS, PS, and HACS), degree of HP (without, HP-1 and HP-2), AT (without and with acid treatment), and C (6\% and $9 \% \mathrm{w} / \mathrm{w})$ on $T_{\text {sol }}$ and $T_{\text {gel }}$, respectively.

and amaranth starch, MS 0.025-0.130) and Chuenkamol et al. ${ }^{[31]}$ (canna starch, MS 0.01-0.11). The supposed reason is the reduced ability of the starch to retrograde. Lawal ${ }^{[32]}$ investigated HP pigeon pea starch (MS 0.06-0.17). Compared to the native starch, the turbidity was indeed significantly lowered due to HP, but the impact of the incremental increase of the MS was marginal. This confirms the results of the present study ( $T_{\text {sol }}$ in Table 1 and Figure $1 \mathrm{~B}, \mathrm{E}, \mathrm{H})$ with gradation of the MS between about 0.07 (HP-1) and 0.15 (HP-1). ${ }^{[1]}$ In particular, inter- and intramolecular repulsion among the bulky HP-groups were strongly suggested to be responsible for the enhanced paste clarity. ${ }^{[32]}$ A similar relationship was revealed for white yam starch pastes. ${ }^{[33]}$ While the clarity of the native sample decreased successive with increasing storage time up to $30 \mathrm{~d}$, the HP resulted in its remarkable increase. However, both the MS level (0.09-0.18) and the storage time (1-30 d) did not impact the clarity significantly. A comparatively slight increase of the paste clarity from about $5.5 \%$ (native) to about $12.5 \%$ (MS 0.033 ) was proved by Woggum et al. ${ }^{[34]}$ for rice starch subjected to HP (MS 0.022-0.033; C of $1 \% \mathrm{w} / \mathrm{w}$; measurement at $25^{\circ} \mathrm{C}$ ).

The additional impact of the AM content was investigated in detail by Shen et al. ${ }^{[35]}$ and Liu et al. ${ }^{[36]}$ For rice starches with different AM contents $(7.0 \%, 19.0 \%$, and $48.5 \% \mathrm{w} / \mathrm{w})$, the difference of the clarity between the native starch and the corresponding HP samples increased systematically with increasing AM content up to about $40 \%$ (storage for $10 \mathrm{~min}$, fresh). The main reason was suggested to be the comparatively high paste turbidity of high AM starches in general (native). However, enhanced storage duration changed the clarity remarkably (24 and $168 \mathrm{~h}$ ) dependent on the starch variety. The lowest AM content resulted in a further increase of the clarity upon storage of about $5 \%$. Yet, medium AM content did not show an effect, while the highest AM content of the starch provoked a significant reduction in the light transmission of up to about $20 \%\left[{ }^{[35]}\right.$ due to extended storage time. Similar relationships were reported for corn starches with varying AM contents $(66 \%, 47 \%, 19 \%$, and 


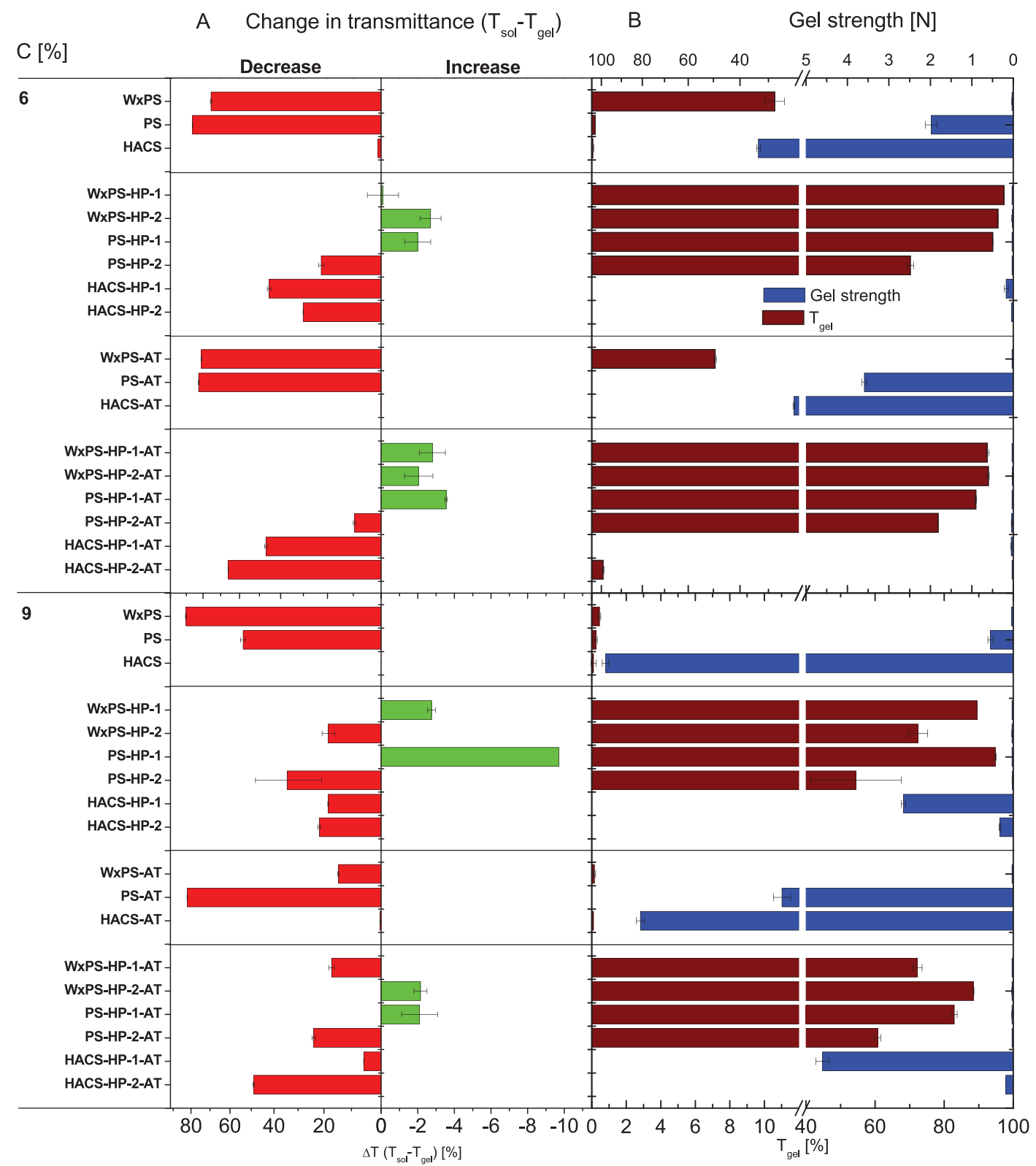

Figure 2. A) Change in $T(\Delta T)$ due to sol-gel transition $\left(T_{\text {sol }}-T_{\text {gel }}\right)$, B) $T_{\text {gel }}$ and gel strength of the starch-water systems (native, single modification, dual modification) in dependence on C (6\% and $9 \% \mathrm{w} / \mathrm{w})$.

$3.3 \% \mathrm{w} / \mathrm{w})$. The clarity of pastes of native starches decreased systematically with an increasing AM content (C of $1 \% \mathrm{w} / \mathrm{w}$; measurement at $25{ }^{\circ} \mathrm{C}$ ), and the HP generally provoked an increase of the same. On the one hand, the relative increase was more pronounced with higher AM content of the starch, but on the other hand, the level of $T$ was incrementally reduced. ${ }^{[36]}$ Altogether, the results obtained accord well with literature data.

Increasing AM content and decreasing $M_{\mathrm{w}}$ of the starch sample, ${ }^{[1]}$ respectively, decreased both $T_{\text {sol }}$ and $T_{\text {gel }}$ (Figure 1A). Moreover, the AT subsequent to HP (dual modification) does not impact the clarity of a starch solution and a starch gel significantly, which was expected based on previous studies of AT starches (single modification). ${ }^{[10,37]}$ Without additional chemical modification like HP or acetylation, which would include the integration of bulky groups into the polysaccharide structure acting as spacers, the AT can result in a $T_{\text {gel }}$ decrease. ${ }^{[37]}$ The partial molecular degradation of the starch polymers, but particularly the cleavage within the AP, provokes the formation and in a manner of speaking, the release of comparatively short and widely unbranched chains, which are presumably exceptionally exposed to fast retrogradation. Development of crystalline structures consequently leads to enhanced light scattering upon cold storage. 


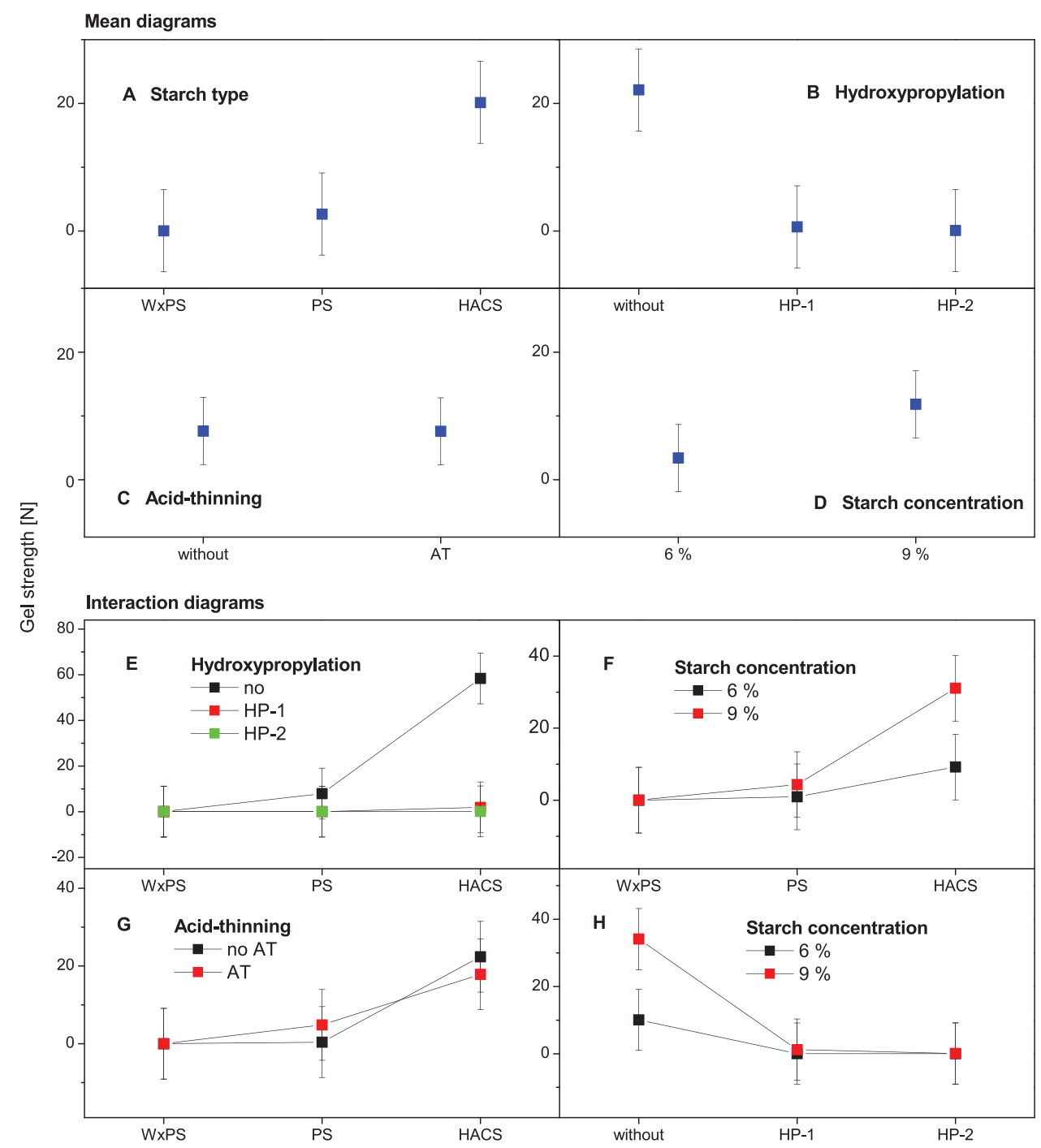

Figure 3. Mean (A-D) and selected interaction diagrams (E-H) with a $95 \%$ confidence interval of the impacts of starch type (WxPS, PS, and HACS), degree of HP (without, HP-1 and HP-2), AT (without and with acid treatment), and C (6\% and $9 \% \mathrm{w} / \mathrm{w})$ on gel strength.

\subsection{Storage-Induced Changes of the Starch Pastes and Gel Characteristics}

Storage of the concentrated starch solutions for a long time period $(168 \mathrm{~h})$ at reduced temperature $\left(5.5 \pm 1.5^{\circ} \mathrm{C}\right)$ changed the $T$. In most cases the $T$ was decreased significantly (Figure 2A, left). Reasons are supposed to be a successive increase of inter-chain interactions accompanied by partial retrogradation and crystallization, the resulting increased light scattering and turbidity of the system, respectively. However, interactions based on intra-molecular associations as well as AM-lipid complexes seem also possible, probably impacting the $T_{\text {gel }}$ in the end. Altogether, a decrease of the $T$ is not necessarily related to formation of a mechanically stable gel network structure, and the gradual increase in some cases (all with potato-based starch samples including HP) could presumably be associated with partial phase separation during the long-term storage (Figure 2A).
The ability of a starch sample to gel depends on several factors, for example, AM/AP ratio, molecular characteristics of the different structure fractions, polymer concentration of the solution, and solution state as well as storage conditions. Within the scope of the present study, the gel strength was found to be positively correlated to the AM content of the starch (native, Figure 2B). The ability to form a mechanically stable gel increased in the order WxPS (no AM), PS (about 24\% w/w AM) and HACS (about $74 \% \mathrm{w} / \mathrm{w}$ AM). The impact "starch type" (AM) was identified to be statistically significant to the gel strength (ANOVA, Table 1), and the gel strength of the potato-based samples was found to be clearly different to that of the HACS (Figure 3A). Since the WxPS does not contain AM, the formation of a 3D (AM based) network is naturally impossible. The possible retrogradation occurrence of longer AP branch chains ${ }^{[38]}$ (DP $\geq 15$ ) is supposedly negligible in terms of development and successive reinforcement of a gel network structure. In contrast, the HACS with an AM content higher than $70 \% \mathrm{w} / \mathrm{w}$ has a remarkable tendency for 
retrogradation and gelation. The strength of the gel prepared with HACS increased with increasing C from about 35 to 90 $\mathrm{N}$ (Figure 2B). The AT of the PS, which results in a partial molecular degradation of the starch polysaccharides, improved the gel strength as expected (PS: 2N, PS-AT: $3.5 \mathrm{~N}$ ) ${ }^{\left[{ }^{[0]}\right.}$ However, AT of the starch genotypes (WxPS and HACS) is not beneficial, and is even contradicting when focused on the improvement of the ability to gel or to produce high gel strength, respectively (Figure 2B). ${ }^{[3]}$ Within the experimental design of the present study, the AT had no statistically significant effect on the gel strength (Table 1, Figure 3C,G). The modification using HP reduced the capacity of the respective starch product to gel significantly (Table 1, Figure 3B), which was more pronounced with an increasing AM content of the starch (Figure 3E), since the WxPSbased samples (WxPS, WxPS-AT) did not form gels anyway. The gelation based on partial retrogradation was impeded by the HP groups. An exception was HACS-HP-1 at $9 \%$ w/w having a gel strength of about $3 \mathrm{~N}$ (Figure 2B), whereupon the hardness of the corresponding dual-modified variety (HACS-HP-1-AT) could be further enhanced by about $50 \%$ to $4.5 \mathrm{~N}$. Moreover, probably the HP resulted a specific susceptibility of the potato-based samples (WxPS-HP, PS-HP) to molecular degradation during paste preparation, ${ }^{[15]}$ which possibly impacts the gelation behavior, too. Overall, the dual approach with modification by means of HP and subsequent AT accomplishes neither acceptable gel strength nor concomitant clarity of the stored system. In contrast, the (inherent) characteristic of the starch product to form a transparent system is accompanied by the elimination of the ability to form a gel structure of sufficient mechanical strength in most cases (Figure 2B). The property of high clarity, which is induced by the incorporation of the HP-groups into the polymer structure acting as spacers, impedes comprehensive inter-chain associations and gelation, respectively. Enhancement of the $\mathrm{C}$ increased the gel strength significantly (Figure 3D), but this trend applies solely to the samples containing AM (PS and HACS, Figure $3 \mathrm{H}$ ), and not to those chemically modified by means of HP (Figure 3F).

When comparing the results with literature data, it should be noted that usually the setback viscosity of rapid visco analyzer (RVA) examinations is used as the characteristic quantity indicating the gelation and the final gel strength, respectively, which is in contrast to the present study. However, the principal behavior of the starch should be represented sufficiently by both methodical approaches, which permits a basic comparison. Decreasing gel strength due to HP was reported comprehensively for various starches and levels of MS elsewhere. However, the impact of incremental MS is not described uniformly. For example, Choi and $\operatorname{Kerr}^{[39]}$ revealed lowered gel strength due to HP, but no significant difference was found in dependence on the MS (HP wheat starches; MS 0.05-0.18). Lawal ${ }^{[32]}$ also reported a reduced setback of HP pigeon pea starch (MS 0.06-0.17) compared to the native starch, which was attributed to restricted structural realignment of the starch polymers. The bulky HP-groups were suggested to prevent the formation of hydrogen bonding among the molecules, thus minimizing the formation of double-helical regions and their accompanying crystallization (retrogradation), which limits at least or even inhibits the development of a polymer network. Moreover, for white yam starch HP with differing MS (MS 0.09-0.18), Lawal et al. ${ }^{[33]}$ found significantly lower viscosity of the HP samples after cooling $\left(50^{\circ} \mathrm{C}\right)$ compared to the native starch. Concretely, the setback decreased from 212 rapid visco units (RVU) for the native starch to $141 \mathrm{RVU}$ (MS 0.09) and systematically to $115 \mathrm{RVU}$ (MS 0.18) with an increasing MS, indicating incremental loss of ability to form a network structure. The percentage retrogradation (DSC experiments) decreased successively from $34 \%$ (native, storage $3 \mathrm{~d}$ ) to $10 \%$ (MS 0.18 , storage $3 \mathrm{~d}$ ), and from $84 \%$ (native, storage $5 \mathrm{~d}$ ) to $21 \%$ (MS 0.18 , storage $5 \mathrm{~d}$ ), respectively. In summary, a significantly reduced setback viscosity (RVA) can be clearly ascribed to a diminished retrogradation tendency, particularly of the $\mathrm{AM}\left(\mathrm{Pal} ;{ }^{[30]} \mathrm{HP}\right.$ corn and amaranth starches; MS 0.025-0.130), which is distinct from the lowered syneresis tendency (freeze-thaw experiments). At the same time, Senanayake et al. ${ }^{[40]}$ proved suppressed retrogradation due to HP (different sweet potato starch cultivars) by means of DSC experiments.

Since the gel strength decreased successively with increasing MS (MS 0.01-0.11), a clear dependency was likewise found based on canna starch samples. ${ }^{[31]}$ Similar results were obtained by Aminian et al. ${ }^{[41]}$ for HP sago starch (MS 0.007-0.66). The cold paste viscosity (native: $105 \mathrm{RVU}$, MS 0.66: $25 \mathrm{RVU}$ ) and the setback (native: 43 RVU, MS 0.66: 9 RVU), respectively, were successively reduced with an increasing degree of modification. A decreasing tendency to syneresis, particularly with increasing MS and decreasing number of freeze-thaw cycles, was attributed to limited structural arrangements of the polymer chains which prevented extensive retrogradation. This was in accord with the findings of Woggum et al. ${ }^{[34]}$ The main reason for successively lowered gel strength with increasing MS was assumed to be the bulky and hydrophilic nature of the HP-groups, which hinder in particular the AM chains from associating and crystallizing. That explains the distinctive loss of the AM containing starch samples' (PS and HACS, Figure 2) ability to gel. The special impact of the AM content was investigated by Liu et al. ${ }^{[36]}$ on corn starch varieties $(66 \%, 47 \%, 19 \%$, and $3.3 \% \mathrm{w} / \mathrm{w}$, respectively). The gel strength (final viscosity at $50{ }^{\circ} \mathrm{C}$ ) decreased remarkably due to HP in the case of the regular starch (19\% w/w AM). However, the respective viscosity of both native high AM genotypes $(47 \%$ and $66 \% \mathrm{w} / \mathrm{w}$ AM) was found to be at a very low level, which most probably indicates an insufficient solution state of the aqueous system (dispersion) after processing by means of the RVA. ${ }^{[42]}$ Native high AM starches usually require rigorous conditions (e.g., pressure cooking) to ensure a good solution state, which is however, a prerequisite for the adequate development of inherent functional properties. Therefore, increasing final viscosity of the high AM genotypes with increasing MS is predominantly related to simply improved swelling, and most likely not to structure development by retrogradation.

A quite different behavior was revealed by Majzoobi ${ }^{[43]}$ for HP oat starch (MS 0.09). HP led to increased gel strength, which is in contrast to the findings reported in the present study. This was attributed to greater granule swelling of the oat starch owing to HP. Moreover, Oladebeye ${ }^{[44]}$ found significantly enhanced cold paste viscosity and setback, respectively, due to HP of different legume starches (lima and jack bean, MS 0.26-0.37 and 0.240.30 , respectively), which was also ascribed to increased dimension of the swollen granule fragments or remnants. The contribution of the particles to the cold paste viscosity enhancement was explained by the embedding in the matrix of the associated polymer network. In general, since the RVA measurements 

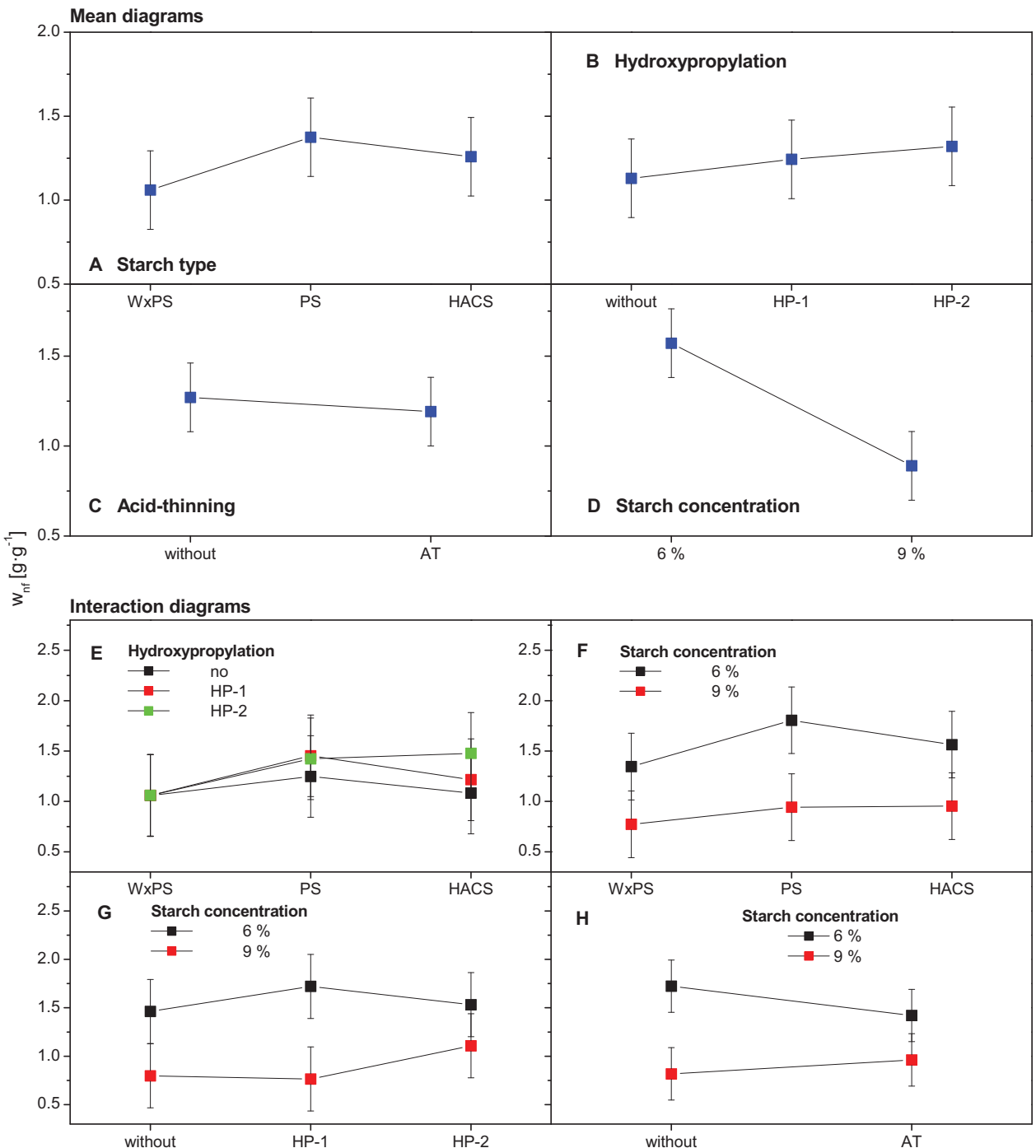

Figure 4. Mean (A-D) and selected interaction diagrams $(E-H)$ with a $95 \%$ confidence interval of the impacts of starch type (WxPS, PS, and HACS), degree of HP (without, HP-1 and HP-2), AT (without and with acid treatment), and C (6\% and $9 \% \mathrm{w} / \mathrm{w})$ on $w_{\text {nf }}$ (freezing).

include the pasting of the starch at a temperature of about $95^{\circ} \mathrm{C}$ in maximum, the characterization of the gel strength by means of the setback viscosity is based on an aqueous system of usually limited solution state.

\subsection{Water Binding in Starch Gels}

The water binding in the stored aqueous starch systems was investigated based on DSC experiments, taking the $w_{\mathrm{nf}}$ as the water fraction very tightly bound to the polymers representing the $\mathrm{WBC}_{\mathrm{gel}}$. It could be hypothesized that an increasing portion of chain-to-chain interaction (H-bonds; retrogradation and crystallization) would reduce the water-to-chain interaction by trend, and hence, reduce the water fraction which is protected from the phase transition from liquid to solid $\left(w_{n f}\right)$. However, none of the factors varied in the study was found to be statistically significant on $w_{\text {nf }}$ (ANOVA, Table 1) except C. This is also obvious from the mean diagrams (Figure 4A-C) and corresponding selected interaction plots (Figure 4E-H). Solely the $\mathrm{C}$ was significant on $w_{n f}$, which is underlined by the mean diagram in Figure 4D. The $w_{\text {nf }}$ decreases from about 1.57 to $0.90 \mathrm{~g} \mathrm{~g}^{-1}$ with an increasing $\mathrm{C}$ from $6 \%$ to $9 \% \mathrm{w} / \mathrm{w}$. The enhancement of C from $6 \%$ to $9 \% \mathrm{w} / \mathrm{w}$ decreases $w_{c}$ remarkably from about 15.7 to $10.1 \mathrm{~g} \mathrm{~g}^{-1}$. At the same time, the probability of inter-chain associations increases concurrently with an increasing volume fraction of the polysaccharides, consequently reducing $w_{\text {nf. }}$. This trend is also apparent in Figure $4 \mathrm{~F}-\mathrm{H}$. Based on the values in Figure 4 D, the different water fractions in the gel are visualized in terms of absolute composition (absolute content), the portion related to the starch (related to dry matter, mass relationship) and the molar ratio (related to AGU, molar relationship) depending on the starch content in Figure 5. Interestingly, independent of $\mathrm{C}$ about $10 \%$ of the water molecules are non-freezable. With a $\mathrm{C}$ of $6 \% \mathrm{w} / \mathrm{w}$, the starch-water system was calculated to contain about 141 water molecules per AGU, 14 of which were non-freezable. Since 


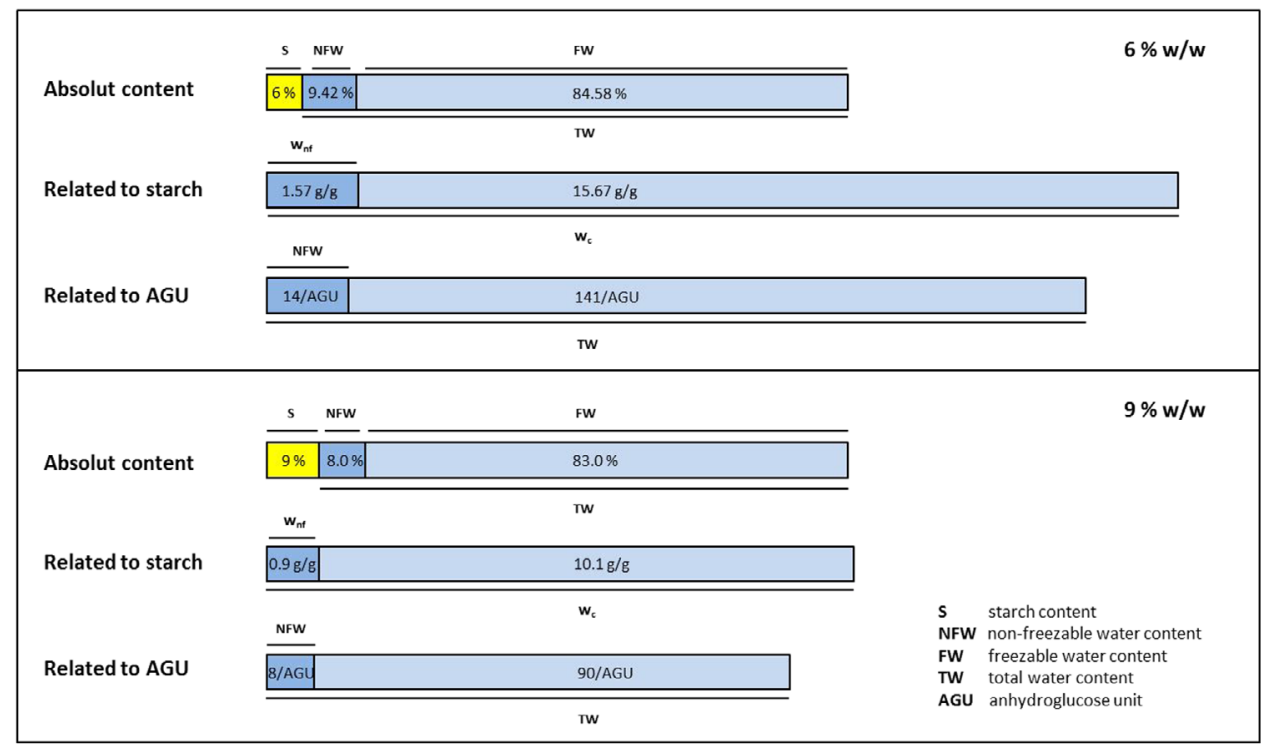

Figure 5. Different water fractions (total, freezable, and non-freezable water) in the gel depending on C ( $6 \%$ and $9 \% \mathrm{w} / \mathrm{w}$ ), exemplarily visualized based on the data in Figure 4D.

the amount of water molecules decreased to 90 per AGU and 8 water molecules were non-freezable, respectively, enhancing the $\mathrm{C}$ to $9 \% \mathrm{w} / \mathrm{w}$, an intensified polymer-polymer interaction is assumed. The freezable water content (about $90 \%$ ) is supposed to be immobilized in the starch-water matrix. Choi and Kerr ${ }^{[39]}$ characterized wheat starch gels by means of proton relaxation measurements using NMR. Enhanced starch concentration in the gel (native) was associated with reduced amount of the less mobile water, which confirms the results of the present study (Figure 4D). Moreover, the portion of the less mobile phase in the gels was reported to increase strongly with an increasing MS of the HP samples (MS 0.05-0.18). This specific relationship was found merely by trend (Figure 4B). For gels prepared with AT potato starch samples, a similar level for $w_{\text {nf }}$ was found (about $0.5-2.0 \mathrm{~g} \mathrm{~g}^{-1}$; gel preparation with $7.5 \% \mathrm{w} / \mathrm{w}$ ). ${ }^{[10]}$ The $w_{\mathrm{nf}}$ decreased with increasing gel strength by trend. Decreasing $w_{\mathrm{nf}}$ with increasing carbohydrate concentration was also revealed for maltodextrins with different DP (solutions and gels; about $0.5-1.0 \mathrm{~g} \mathrm{~g}^{-1}$ ) elsewhere. ${ }^{[45,46]}$ In general, the level of $w_{\text {nf }}$ for aqueous starch systems or starch gels, respectively, was found to be significantly higher compared to granular starches. ${ }^{[47,48]}$

\subsection{Investigation of Starch Mixtures}

Based on the data obtained for the native, single-modified (HP or AT) and dual-modified (-HP-X-AT) starch samples, mixtures were prepared and investigated in terms of gel strength and respective $T_{\text {gel }}$. The components were selected with regard to highest gel strength (HACS) and very high $T$ after cold storage $\left(T_{\text {gel }}\right)$ indicating no remarkable tendency to retrogradation (WxPS-HP-2-AT, PS-HP-1-AT, and PS-HP-1) in contrast. It was proposed to identify a mixing ratio assuring the highest specificity of both functional properties, that is, sufficient gel strength as well as $T_{\text {gel }}$, effectively as a compromise-based result. The data are summa-

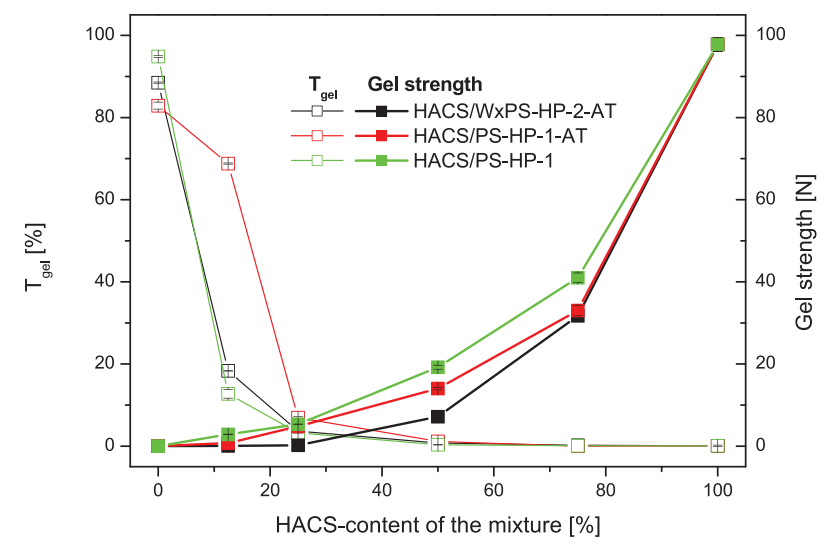

Figure 6. $T_{\text {gel }}$ and mechanical strength of stored starch pastes $(9 \% \mathrm{w} / \mathrm{w}$, $168 \mathrm{~h}$ at $5.5^{\circ} \pm 1.5^{\circ} \mathrm{C}$ ) prepared with mixtures of HACS and WxPS-HP-2-AT, PS-HP-1-AT, and PS-HP- 1 of different mixing ratios (0/100: pure HACS native, 12.5/87.5: 12.5\% HACS, 25/75: 25\% HACS, 50/50: 50\% HACS, 75/25: 75\% HACS, and 100/0: 100\% HACS).

rized in Figure 6. Against the initial expectation, the specificity of both investigated characteristics did not follow a linear relationship dependent on the respective mixing ratio. Independent of the modified starch components used, which were essentially resistant to retrogradation and accompanied development of turbidity ( $\left.T_{\text {gel }} 83-95 \%\right)$, the clarity dropped considerably, even at a substitution level of $12.5 \%$ and $25 \%$ (w/w) with HACS. Since there was no remarkable enhancement of the gel strength at this substitution level, the strong increase of turbidity could probably be predominantly ascribed to AM-lipid complex formation and granular remnants affecting the light scattering behavior in the paste. ${ }^{[9]}$ Serious retrogradation involving the comprehensive development of a 3D AM network seems unlikely. Further increase of the HACS content in the starch mixture to $50 \%, 75 \%$, 
and $100 \%(\mathrm{w} / \mathrm{w})$, respectively, did indeed successively increase the archived mechanical strength, but the progression was not linear-dependent on the mixing ratio. In concluding the present results, mixtures of starches differing strongly in terms of the specificity of the gel strength and the $T_{\text {gel }}$ were found to be unsuitable for combining the required functional properties if quasi compromise-based. The synergistic implementation of a starch with the desired properties by preparing mixtures was not revealed during the present examinations. The results are in accordance with that reported elsewhere for mixtures of AT corn starch genotypes. ${ }^{[3]}$

\section{Conclusions}

The dual approach including HP and subsequent AT of starches was targeted to synergistically combine different desired functional properties. Since the application of starch as a gelling agent in gelled sweets requires the capability to form gels with high mechanical strength and concurrently high system clarity, both properties were intended to be incorporated as inherent characteristics of the starch via modification. Moreover, since both gel network formation and development of turbidity are controlled by the tendency to retrogradation and thus the molecular composition and the starch structure, respectively, starches with strongly different AM/AP ratios were used for the investigation. The HP of the starch results an increase of the $T_{\mathrm{sol}}$, and normally a lower reduction of $T$ owing to cold storage in contrast. However, that does not apply to the HACS, most likely due to the comparatively high lipid content (AM-lipid complex formation) as well as the high AM content resulting in comprehensive retrogradation. Since the ability to form stable gels is not lost completely due to HP in the case of two particular HACS-based samples (HACSHP-1 and HACS-HP-1-AT), these modified starches could be potentially advantageous in a formulation including glucose syrup and saccharose. The higher dry matter content of such formulation may be expected to be a generally enhanced $T$. Altogether, the synergistic implementation of two actually opposing properties in a starch product to produce a starch-based alternative to, for example, gelatin and pectin as a gelling agent in gelled sweets was not comprehensively successful within the present study.

\section{Acknowledgements}

This research was financially supported by the German Federal Ministry for Economic Affairs and Energy (BMWi) within the scope of the Industrial Collective Research (IGF) of the German Federation of Industrial Research Associations (AiF; research project $20248 \mathrm{~N}$ ). The authors would like to thank Emsland-Stärke $\mathrm{GmbH}$ for preparing the HP starches. The authors also thank Mrs. Ewgenia Kuhl for her assistance in performing numerous experiments and Ms. Donna Hastings for checking the manuscript linguistically.

\section{Data Availability Statement}

Author elects to not share data.

\section{Conflict of Interest}

The authors declare no conflict of interest.

\section{Keywords}

dual modification, gel properties, hydroxypropylation, non-freezable water, starch genotypes

Received: July 10, 2020

Revised: August 20, 2020

Published online:

[1] M. Ulbrich, E. Flöter, Starch/Staerke 2020, 72, 2000015.

[2] M. Ulbrich, T. A. Terstegen, E Flöter, Starch/Staerke 2018, 71 , 1800080.

[3] M. Ulbrich, J. M. Daler, E. Flöter, Food Hydrocolloids 2020, 98, 105249.

[4] M. Ott, E. Hester, Cereal Chem. 1965, 42, 476.

[5] S. G. Ring, Starch/Staerke 1985, 37, 80.

[6] C. J. A. M. Keetels, T. van Vliet, P. Walstra, Food Hydrocolloids 1996, $10,363$.

[7] C. J. A. M. Keetels, T. van Vliet, P. Walstra, Food Hydrocolloids 1996, 10, 355.

[8] E. Bertoft, G. A. Annor, X. Shen, P. Rumpagaporn, K. Seetharaman, B. R. Hamaker, Carbohydr. Polym. 2016, 140, 113.

[9] S. A. S. Craig, C. C. Maningat, P. A. Seib, R. C. Hoseney, Cereal Chem. 1989, 66, 173.

[10] M. Ulbrich, E. Flöter, Starch/Staerke 2019, 71, 1900176

[11] Z. Fu, L. Zhang, M.-H. Ren, J. N. BeMiller, Starch/Staerke 2019, 71, 1800167

[12] M. Ulbrich, C. Natan, E. Flöter, Starch/Staerke 2014, 66, 903.

[13] M. Ulbrich, V. Lampl, E. Flöter, Starch/Staerke 2016, 68, 885.

[14] M. Ulbrich, J. M. Daler, E. Flöter, Carbohydr. Polym. 2019, $219,172$.

[15] M. Ulbrich, E. Flöter, Starch/Staerke 2020. https://doi.org/10.1002/ star.202000145.

[16] A. E. McPherson, J. Jane, Carbohydr. Polym. 1999, 40, 57.

[17] S.-T. Lim, T. Kasemsuwan, J.-L. Jane, Cereal Chem. 1994, 71, 488.

[18] Y. Takeda, S. Hizukuri, Carbohydr. Res. 1982, 102, 321.

[19] Y. Ai, J.-L. Jane, in Starch in Food: Structure, Function and Applications (Eds: M. Sjöö, L. Nilsson), Elsevier, Duxford, UK 2018, Ch. 3.

[20] J. Singh, L. Kaur, Advances in Potato Chemistry and Technology, Elsevier, Burlington, MA 2009

[21] W. R. Morrison, B. Laignelet, J. Cereal Sci. 1983, 1, 9.

[22] J. B. South, W. R. Morrison, O. E. Nelson, J. Cereal Sci. 1991, 14, 267.

[23] W. R. Morrison, M. N. Azudin, J. Cereal Sci. 1987, 5, 35.

[24] W. R. Morrison, J. Cereal Sci. 1988, 8, 1.

[25] W. R. Morrison, T. P. Milligan, M. N. Azudin, J. Cereal Sci. 1984, 2, 257.

[26] A.-C. Eliasson, H. Finstad, G. Ljunger, Starch/Staerke 1988, 40, 95.

[27] K. W. Boltz, D. B. Thompson, Cereal Chem. 1999, 76, 204.

[28] M. Kugimiya, J. W. Donovan, R. Y. Wong, Starch/Staerke 1980, 32, 265.

[29] L. A. Bello-Pérez, F. Ortíz-Maldonado, J. Villagómez-Mendez, J. F. Toro-Vazquez, Starch/Staerke 1998, 50, 383.

[30] J. Pal, R. S. Singhal, P. R. Kulkarni, Carbohydr. Polym. 2002, 48, 49.

[31] B. Chuenkamol, C. Puttanlek, V. Rungsardthong, D. Uttapap, Food Hydrocolloids 2007, 21, 1123.

[32] O. S. Lawal, LWT-Food Sci. Technol. 2011, 44, 771.

[33] O. S. Lawal, O. O. Ogundiran, E. K. Adesogan, B. M. Ogunsanwo, O. A. Sosanwo, Starch/Staerke 2008, 60, 340.

[34] T. Woggum, P. Sirivongpaisal, T. Wittaya, Food Hydrocolloids 2015, 50, 54.

[35] Y. Shen, N. Zhang, Y. Xu, J. Huang, M. Yuan, D. Wu, X. Shu, Int. J. Biol. Macromol. 2019, 128, 775 .

[36] H. Liu, L. Ramsden, H. Corke, Carbohydr. Polym. 1999, 40, 175

[37] M. Ulbrich, I. Wiesner, E. Flöter, Starch/Staerke 2015, 67, 424. 
[38] S. G. Ring, P. Colonna, K. J. I'Anson, M. T. Kalichevsky, M. J. Miles, V. J. Morris, P. D. Orford, Carbohydr. Res. 1987, 162, 277.

[39] S. G. Choi, W. L. Kerr, Carbohydr. Polym. 2003, 51, 1.

[40] S. Senanayake, A. Gunaratne, K. K. D. S. Ranaweera, A. Bamunuarachchi, Int. J. Food Sci. 2014, 148982.

[41] M. Aminian, A. M. Nafchi, M. Bolandi, A. K. Alias, Starch/Staerke 2013, 65, 686.

[42] Y. Ai, J.-L. Jane, Starch/Staerke 2015, 67, 213.
[43] M. Majzoobi, B. Saberi, A. Farahnaky, G. Mesbahi, Int. J. Food Eng. 2014, 10, 657

[44] A. O. Oladebeye, A. A. Oshodi, I. A. Amoo, A. A. Karim, Starch/Staerke 2013, 65, 762.

[45] S. Radosta, F. Schierbaum, F. Reuther, H. Anger, Starch/Staerke 1989, 41, 395.

[46] S. Radosta, F. Schierbaum, Starch/Staerke 1990, 42, 142.

[47] M. Wootton, A. Manatsathit, Starch/Staerke 1983, 35, 92.

[48] M. Wootton, A. Bamunuarachchi, Starch/Staerke 1978, 30, 306. 